\title{
High glucosinolate broccoli: a delivery system for sulforaphane
}

\author{
Golge Sarikamis · Julietta Marquez • \\ Ruth MacCormack · Richard N. Bennett • \\ Jeremy Roberts · Richard Mithen
}

Received: 4 October 2005/ Accepted: 28 June 2006/Published online: 27 September 2006

(C) Springer Science+Business Media B.V. 2006

\begin{abstract}
The development of hybrid broccoli genotypes with enhanced levels of 4-methylsulphinylbutyl glucosinolate, the precursor of anticarcinogenic isothiocyanate sulforaphane (SF), by introgressing genomic segments from the wild ancestor Brassica villosa is described. We demonstrate that to obtain enhanced levels of either 3-methylsulphinylpropyl or 4-methylsulphinylbutyl glucosinolate it is necessary to have $B$. villosa alleles in either a homozygous or heterozygous state at a single quantitative trait locus (QTL) on $\mathrm{O} 2$. The ratio of these two glucosinolates, and thus whether iberin or SF is generated upon hydrolysis, is determined by the presence or absence of
\end{abstract}

G. Sarikamis · J. Marquez

Division of Agricultural and Environmental Sciences, University of Nottingham, Sutton Bonnington, LE12 5RD, UK

R. N. Bennett $\cdot$ R. Mithen $(\varangle)$

Phytochemicals and Health Programme, Institute of Food Research, Colney Lane, Norwich NR4 7UA, UK

e-mail: Richard.mithen@bbsrc.ac.uk

R. MacCormack

John Innes Centre, Colney Lane, Norwich NR4 7UH, UK

J. Roberts

Division of Plant Science, University of Nottingham, Sutton Bonnington LE12 5RD, UK
B. villosa alleles at this QTL, but also at an additional QTL2 on O5. We further demonstrate that following mild cooking high glucosinolate broccoli lines generate about three fold higher levels of SF than conventional varieties. Commercial freezing processes and storage of high glucosinolate broccoli maintains the high level of glucosinolates compared to standard cultivars, although the blanching process denatures the endogenous myrosinase activity.

Keywords Broccoli · Glucosinolates · Isothiocyanates $\cdot$ Sulforaphane $\cdot$ Iberin $\cdot$ Breeding

\section{Introduction}

Consumption of broccoli (Brassica oleracea var. italica) is associated with a reduction in risk of prostate cancer (Joseph et al. 2004), lung cancer (Spitz et al. 2000) and colorectal adenomas (Lin et al. 1998). The anticarcinogenic activity is most likely to be due to activity of the isothiocyanates iberin (1-isothiocyanato-3-methylsulfinylpropane, IB) and sulforaphane (1-isothiocyanato-4-methylsulphinylbutane, SF, Fig. 1), derived, respectively from 3-methylsulphinylpropyl (3-MSP) and 4-methylsulphinylbutyl (4-MSB) glucosinolates that accumulate in the florets of broccoli. Broccoli also contains glucosinolates with indolyl 


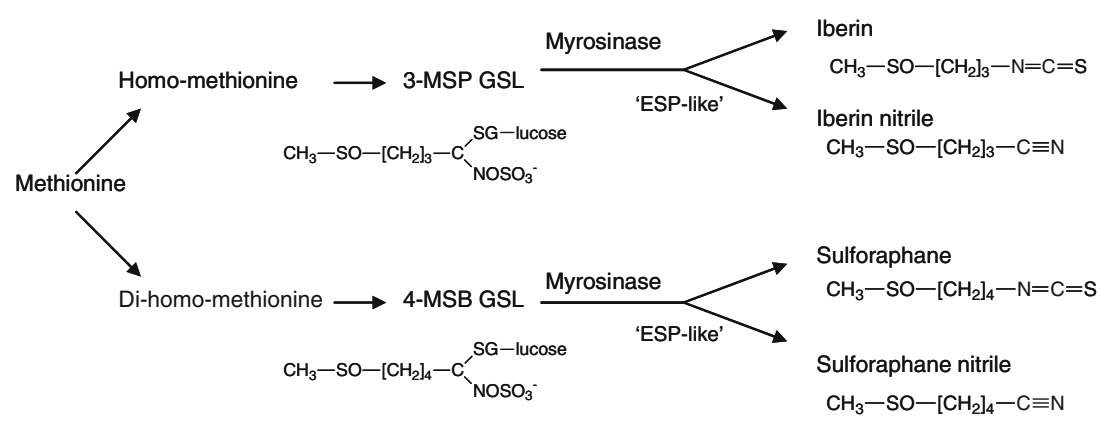

Fig. 1 Structure and degradation of 3-methylsulphinylpropyl (3-MSP) and 4-methylsulphinylbutyl (4-MSB) glucosinolate. The ratio of the two glucosinolates is determined by the extent of methionine elongation,

side chains which degrade to provide indole compounds, such as indole-3-carbinol (I3C), which are metabolized to bioactive compounds such as 3,3'-di-indolylmethane (DIM), that have also been associated with anticarcinogenic activity (Bonnesen et al. 2001; Nachshon-Kedmi et al. 2004). However, the association between broccoli consumption, cancer risk and glutathione $S$ transferase genotype (Joseph et al. 2004; Lin et al. 1998; Spitz et al. 2000) suggests that isothiocyanates may be of greater importance than indole compounds in modulating risk.

Initial interest in SF was due to its potent ability to induce phase II enzymes, such as quinone reductase, glutathione- $S$-tranferases and UDP-glucuronosyl transferases, via ARE-mediated transcription. This is likely to be due to the rapid change in redox potential within cells following SF absorption and glutathione depletion, leading to dissociation of the transcription factor Nrf2 with the Keap1 protein, translocation of Nrf2 to the nucleus and its binding to ARE domains in a suit of phase II detoxification genes leading to transcription (Dinkova-Kostova et al. 2002). To what extent ARE-mediated transcription of detoxification enzymes in vivo accounts for the anticarcinogenic activity of SF or broccoli is uncertain. Several recent studies have demonstrated that sulforaphane can induce cell cycle arrest in a variety of cell types, including prostate (Chiao et al. 2002; Fimognari et al. 2002a; Wang et al. 2004), lymphocyte (Fimognari et al. 2002a, b), colon (Gamet-Payrastre et al. 2000) and mammary (Jackson and Singletary 2003). In a determined by genes within the introgressed segments on $\mathrm{O} 2$ and $\mathrm{O5}$. The ratio of isothiocyanates and nitriles produced depends upon the activity ESP

similar manner, several studies have also reported the ability of sulforaphane to induce apoptosis in a range of cell lines (Bonnesen et al. 2001; Chiao et al. 2002; Fimognari et al. 2002b; Gamet-Payrastre et al. 2000; Kim et al. 2003). The mechanisms underlying these physiological processes have not been fully elucidated, although the induction of c-Jun NH(2)-terminal kinase (JNK) signal transduction pathway (JNK) and activation of caspases has been implicated in apoptosis (Chen et al. 1998; Chiao et al. 2002; Hu et al. 2003). A much smaller number of studies have been undertaken with IB, which have shown that it has similar activity (Kore et al. 1993; Munday and Munday 2004; Wang et al. 2005).

The anticarcinogenic activity of SF has led to several studies on the genetic and environmental factors that determine the accumulation of its precursor, 4-MSB in florets of broccoli (Abercrombie et al. 2005; Farnham et al. 2004, 2005; Jeffery et al. 2003). While these studies have concentrated on existing broccoli cultivars and breeding lines, in order to develop broccoli cultivars that can deliver enhanced levels of anticarcinogenic isothiocyanates over and above those obtained from the existing range of broccoli cultivars, Faulkner and colleagues (Faulkner et al. 1998) crossed a wild relative of broccoli, B. villosa, which had high levels of 3-methylthiopropyl glucosinolate compared to broccoli, and showed that the $F_{1}$ hybrids, which expressed high levels of 4-MSB, had enhanced ability to induce quinone reductase in cell cultures. Mithen and colleagues (Mithen et al. 2003) subsequently 
described the use of these hybrids to develop broccoli breeding lines and experimental hybrids with enhanced levels of 3-MSP and 4-MSB. They showed that allelic variation at two QTLs were of greatest potential importance in determining glucosinolate content. Variation at one of these, QTL-1, affected both the total level and the ratio of 3-MSP and 4-MSB glucosinolates. It was not possible to distinguish whether this was due to the action of a single gene, or to separate, but closely linked, genes.

In addition to defining the genetic basis of differences in glucosinolate accumulation, it is important to evaluate whether the differences in glucosinolate content is correlated with the differences in the amount of SF that different genotypes of broccoli can deliver. Previous studies had shown that when raw tissue is hydrolyzed high glucosinolate inbred lines produced mainly isothiocyanates whereas Marathon produced mainly nitriles (Mithen et al. 2003), and this difference was reflected in their abilities to induce quinone reductase in a mouse hepatoma cell line. The production of nitriles as opposed to ITCs is likely to be due to the greater activity of a protein similar to the epithiopsecifier protein (ESP) that has been characterized in B. napus and Arabidopsis thaliana (Foo et al. 2000; Lambrix et al. 2001; Matusheski et al. 2004). Thus the difference in SF production in broccoli genotypes will be due to differences in 4-MSB GSL content, determined by both genetic and environmental factors, combined with differences in the efficiency of conversion to SF, determined by ESP activity. However, as the ESP-like protein in broccoli has been shown to be readily denatured by heating (Matusheski et al. 2004), and as broccoli is usually cooked before eating, the activity of the ESP-like protein is probably of marginal significance to the health properties of broccoli, except when broccoli is consumed raw. However in order to assess potential SF production from different cultivars with different glucosinolate contents it is necessary to consider the potential contribution of ESP to SF production, particularly if there is a significant difference in the ratio of SF and SF-nitrile produced by different cultivars

In the current paper we describe the extension of this breeding programme to produce high- glucosinolate broccoli hybrids. We describe the effect of allelic variation at a microsatellite locus that is coincident with a quantitative trait locus on O5 that affects glucosinolate expression, and contrast to allelic variation at a second quantitative trait locus on $\mathrm{O} 2$, as previously described (Mithen et al. 2003). We further report on the levels of sulforaphane derived from high glucosinolate broccoli and standard broccoli following mild cooking (to denature ESP), and glucosinolate levels in high glucosinolate and standard broccoli following freezing and storage.

\section{Materials and methods}

\section{Glucosinolate analysis}

Extraction of glucosinolates, conversion to desulfoglucosinolates and analysis by HPLC was as described previously (Magrath et al. 1994). 2-Propenyl glucosinolate, which is not synthesized in broccoli, was used as the internal standard. Confirmation of the peaks was by mass spectrometry as described previously (de Quiros et al. 2000).

\section{Analysis of isothiocyanates and nitriles}

Sulforaphane was quantified in two ways. Within the selection programme and for the initial study on the effects of cooking, extraction and analyses of isothiocyanates was performed as described previously (Mithen et al. 2003). Briefly, broccoli florets, either raw or after cooking, were freeze dried and ground to a fine powder. Between 100 and $500 \mathrm{mg}$ was accurately weighed and hydrolyzed by adding $2 \mathrm{ml}$ of water. After $30 \mathrm{~min}, 3 \mathrm{ml}$ of hot methanol were added and the solution centrifuged. The supernatant was filter through $0.2 \mu \mathrm{m}$ filter and frozen until analyzed by LC-MS, as described previously (Mithen et al. 2003). Calibration curves for quantification of sulforaphane were produced using DL-sulforaphane obtained from ICN Pharmaceuticals Ltd., Basingstoke, Hampshire, UK, and for sulforaphane nitrile using DL-sulforaphane nitrile obtained from Dr J Rossiter, Imperial College, London, UK. Sulforaphane analysis of the broccoli soups was by LC-UV. A $1.5 \mathrm{ml}$ sample was centrifuged 
$\left(17,000 \mathrm{~g}, 4^{\circ} \mathrm{C}, 20 \mathrm{~min}\right)$ followed by filtration of the supernatant $(0.2 \mu \mathrm{m}$ PTFE aqueous filter; Chromos Express, Macclesfield, UK) into HPLC vials. The samples were analyzed by LC-UV in combination with full scan positive ion mode electro-spray mass spectrometry using an Agilent HP1100 system (binary pump, thermostaticallycontrolled auto-sampler and column oven set at $10^{\circ} \mathrm{C}$ and $30^{\circ} \mathrm{C}$ respectively, and a photodiode array detector set to collect data from 200$600 \mathrm{~nm}$ overall and a specific wavelength of $234 \mathrm{~nm}$ ) coupled to an Agilent SL MSD; solvents and gradient as detailed in the multi-purpose phytochemical method as described previously (Bennett et al. 2004)

Development of inbred lines and GSLenriched novel hybrids

The development of inbred lines was undertaken at a field site near Nottingham, UK. The breeding scheme to develop high glucosinolate broccoli hybrids is shown in Fig. 2. The development of the line 69, which is homozygous for $B$. villosa alleles at within two introgressed segments on $\mathrm{O} 2$ and O5 (Fig. 3A), and the experimental hybrid, SB1, has been described previously (Mithen et al. 2003). SB1 was crossed to a commercial inbred line, $\mathrm{Br} 9$, and the progeny grown and analyzed for glucosinolates. Eight individuals were selected and self pollinated. 192 plants were raised from these eight plants and grown in field plots along with plants of the cultivars Marathon and Green Duke and Br9. Glucosinolates were quantified in florets, and tissue hydrolyzed and isothiocyanates and nitriles quantified. Plants were genotyped at OI12-F02, which is a marker for QTL-2 (see above). A single plant, 48-13, was selected which produced $>50 \% 3$-MSP GLS, which is a marker for a plant being homozygous for B. villosa at QTL-1, (Mithen et al. 2003), but was heterozygous at QTL-2 based upon microsatellite analyses. It addition, 48-13 produced predominantly isothiocyanates upon hydrolysis.

48-13 was crossed to $\mathrm{Br} 9$, and 50 plants grown in field plots, along with 70 selfed progeny of 48-13 and 35 plants of the standard broccoli cultivar Marathon. Plants were genotyped at the microsattelite locus O112-F02, and analyzed for glucosinolates and isothiocyanates. A single selfed plant, 48-13-4 was selected that was homozygous for B. villosa alleles at O112-F02, and crossed with Br9. The [48-13 × Br9] hybrids were similar in appearance to commercial cultivars.

Microsatellite assays

In a preliminary screen of microsatellite markers linked to the QTLs described previously (Mithen et al. 2003), it was found that primers for the microsatellite marker OI12-F02 (Forward primer: GGCCCATTGATATGGAGATG; reverse primer CATTTCTCAATGATGAATAGT; http:// www.ukcrop.net/perl/ace/tree/BrassicaDB?name= SSR \%3AOl12-F02andclass=Microsatellite) amplified a single allele of about $250 \mathrm{bp}$ from the

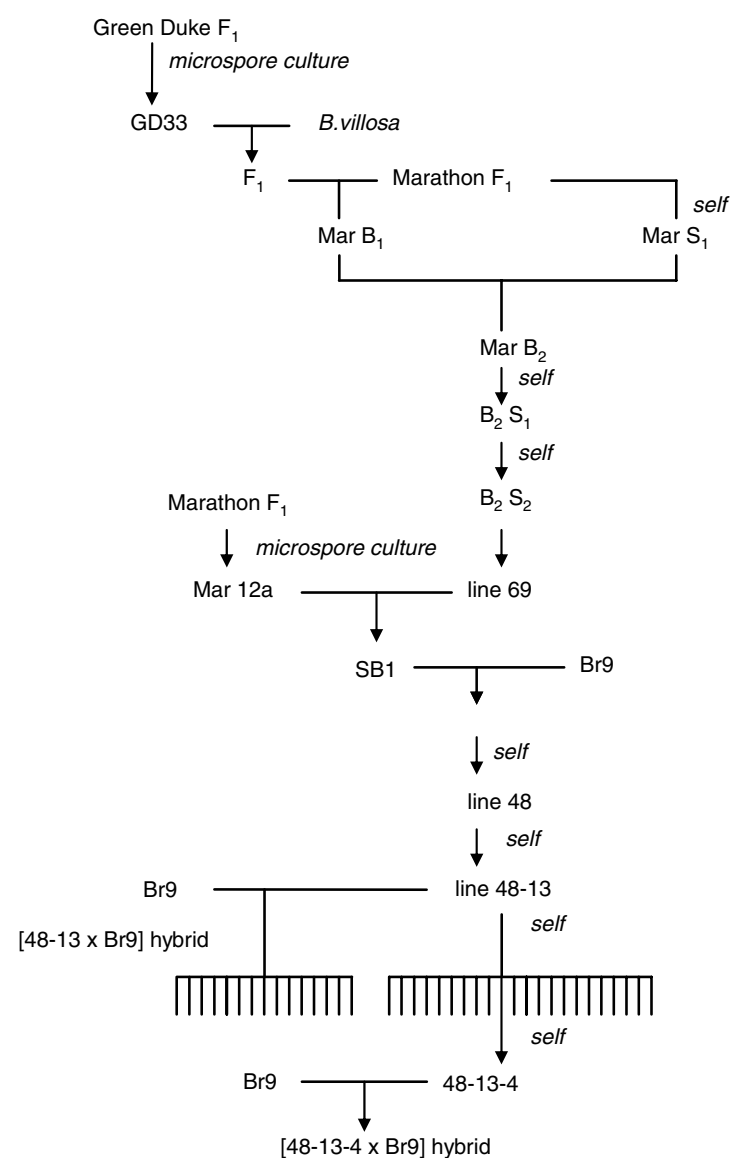

Fig. 2 Summary of the breeding scheme to develop high glucosinolate broccoli. The initial part of the breeding programme has been described in more detailed by Mithen and colleagues (Mithen et al. 2003) 
A

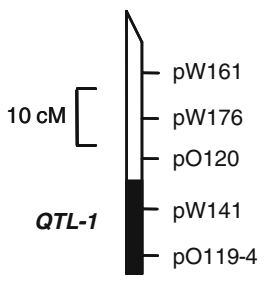

$\mathrm{O} 2$

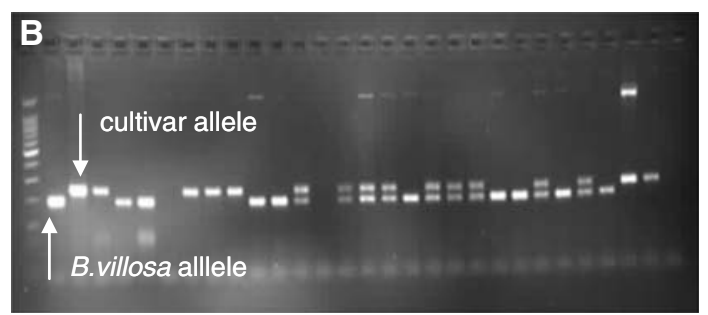

Fig. 3 (A) The two QTLs that have the major affect on glucosinolate content, as described previously (Mithen et al. 2003). (B) Segregation of the microsatellite marker OI12-F02, a marker for QTL-2, in the self of 48-13, showing a 1:2:1 segregation of alleles from B. villos $a$ and cultivar sources

cultivars Marathon, Green Duke and the breeding lineBr9, but an allele of $200 \mathrm{bp}$ from B. villosa, and that this polymorphism cosegregated with the RFLP marker pW114 which is within the introgressed $B$. villosa segment on $\mathrm{O} 5$ in the high glucosinolate breeding lines (Mithen et al. 2003). This marker has also been shown to be linked to pW114a on LG15 of B. napus (http://www.ukcrop. net/perl/ace/pic/BrassicaDB?name=N15_BBSRCSSR\&class= Map; Lowe et al. 2004). Thus OI12F02 was used to identify plants with $B$. villosa alleles at QTL-2, sensu (Mithen et al. 2003). PCR reaction volume was $10 \mu \mathrm{l}$; containing $1 \mu \mathrm{l} 10 \times$ Buffer, $1.5 \mathrm{mM} \mathrm{MgCl}_{2}, 0.08 \mathrm{mM}$ dNTPs, $2 \mu \mathrm{M}$ each primer, $50 \mathrm{ng}$ of template DNA, $0.1 \mathrm{U}$ Red Hot DNA Polymerase (Abgene) and 7.32 $\mu$ l molecular grade water. Reactions without DNA were included as negative controls. GeneAmp ${ }^{\circledR}$ PCR System 9700, has been used for the amplification. Hot start PCR were carried out with a pre-amplification at $94^{\circ} \mathrm{C}$ for $1 \mathrm{~min}$ followed by $72^{\circ} \mathrm{C}$ for $30 \mathrm{~s}$. The amplification conditions were 35 cycles; $20 \mathrm{~s}$ at $94^{\circ} \mathrm{C}$ for denaturation, $30 \mathrm{~s}$ at $52-56^{\circ} \mathrm{C}$ for annealing (depending on the primer) and $1 \mathrm{~min}$ at $72^{\circ} \mathrm{C}$ for extension followed by a $10 \mathrm{~min}$ at $72^{\circ} \mathrm{C}$ and holding temperature $4^{\circ} \mathrm{C}$. PCR products were separated on a $1.5 \%(\mathrm{w} / \mathrm{v})$ agarose gel stained with ethidium bromide at a concentration of $10 \mathrm{mg} / \mathrm{ml}$, and run at around $80 \mathrm{~V}$ for $30 \mathrm{~min}$. They were run with 100 bp DNA ladder (Promega). The products were visualized under UV light and sized relative to the DNA ladder.

\section{Sulforaphane production following cooking}

As a preliminary study, florets of Marathon were blanched for varying lengths of time in boiling water. Following blanching, florets were freeze dried, and glucosinolates extracted in $70 \%$ hot methanol as described above. Alternatively glucosinolates were hydrolyzed by the addition of water and isothiocyanates and nitriles analyzed as described above. To investigate isothiocyanate production from high glucosinolate broccoli compared to standard broccoli, [48$13 \times$ Br9] hybrids, Marathon and the cultivar Iron were grown at a site near Terrington, UK that had moisture and nitrogen retentive soils. Heads were harvested from 50 plants each of [48-13 × Br9], Iron and Marathon, and bulked together. Individual soup portions of the three hybrids were prepared by cooking $100 \mathrm{~g}$ of florets (which may have came from different plants) with $150 \mathrm{ml}$ water for $90 \mathrm{~s}$ on high power in a $700 \mathrm{~W}$ microwave oven followed by homogenisation. The broccoli soup was stored frozen at $-20^{\circ} \mathrm{C}$ until analysis. Analysis of sulforaphane was by LC-UV-MS, as described above.

Glucosinolate content following blanching and freezing

To investigate the effect of blanching and freezing on glucosinolate expression, [48-13-4 $\times$ Br9] hybrids along with the cultivars Marathon and Heritage were grown at an additional field site near Boston, UK in 2004. Heads were harvested and cut into small florets of about $30 \mathrm{~g}$. Florets were blanched for $80 \mathrm{~s}$ at $90.5^{\circ} \mathrm{C}$, frozen at $31^{\circ} \mathrm{C}$, and sealed in plastic bags and stored at $20^{\circ} \mathrm{C}$ until analysed. 


\section{Results}

Genetic analysis of glucosinolate accumulation in breeding lines

48-13 was selected for subsequent analysis as it was shown to possess high levels of 3-MSP GSL and 4-MSB GSL, to convert the majority of its glucosinolates into isothiocyanates and to have reasonable agronomic characters. Moreover, this plant was heterozygous at O112-F02. Hence, this plant was used to study the effect of allelic variation at this locus, which is coincident with QTL-2 on glucosinolate accumulation (Fig. 3A).

Glucosinolate content of selfed progeny of 4813 and $[48-13 \times \mathrm{Br} 9]$

Of the 70 plants of the 48-13 selfed populations, 25 were homozygous for the $B$. villosa allele, 30 were heterozygous and 15 were homozygous for the cultivar allele. This ratio is not significantly different from 1:2:1 $\left(\chi^{2}=4.28, d f=2, p<0.05\right)$. Although all plants had $>50 \% 3$-MSP, due to the homozygous $B$. villosa alleles at QTL-1, the genotype at QTL-2 had a significant effect on the 3-MSP/4-MSB ratio; plants with $B$. villosa alleles had a greater 3-MSP/4-MSB ratio than those without $B$. villosa alleles. Genotype at QTL-2 had no overall effect on the combined level of these glucosinolates. (Fig. 4). Of the 32 [48-13 × Br9] plants, 15 were homozygous for the cultivar allele and 17 were heterozygous, not significantly different from a 1:1 ratio $\left(\chi^{2}=0.125, d f=1\right.$; $p<0.05)$. Within this population, all plants have $>50 \% 4-\mathrm{MSB}$, indicative of having a cultivar allele at QTL-1. As with the selfed population, plants with a $B$. villosa allele at QTL-2 had higher proportion of 3-MSP than those which were heterozygous. Thus, the total level of 3-MSP and 4MSB glucosinolates is predominantly dependent upon the presence of B. villosa alleles at QTL-1, but the ratio of these glucosinolates is dependent upon genotype at both QTL-1 and QTL2.

Sulforaphane production from high glucosinolate and standard broccoli

For this study we grew the [48-13-4 $\times$ Br9] hybrid, which would be heterozygous at both
QTL1 and QTL2 for the B. villosa and cultivar alleles, and Marathon, along with the cultivar Iron, at a field site with nitrogen retentive soils. As a preliminary study we investigated the effect of cooking on isothiocyanate production from Marathon. Cooking for various lengths of time, without subsequent homogenization had no effect on glucosinolate content (Fig. 5A). When homogenized after cooking, isothiocyanates production initially increased after cooking, and then fell, so that after 4 min of cooking no ITCs were produced (Fig. 5B). Thus, to compare sulforaphane from Marathon and high glucosinolate hybrids, we cooked florets for $1.5 \mathrm{~min}$ each, and analyzed ITCs after homogenization. The levels of 4-MSB within [48-13 $\times$ Br9] were significantly higher than those in either Marathon or Iron. Likewise, there was a higher concentration of SF in the soups made from these three genotypes. Despite the cooking, there was still a greater overall conversion of 4-MSB to SF in the [48-13-4 × Br9] hybrid compared to either Marathon or Iron (Table 1)

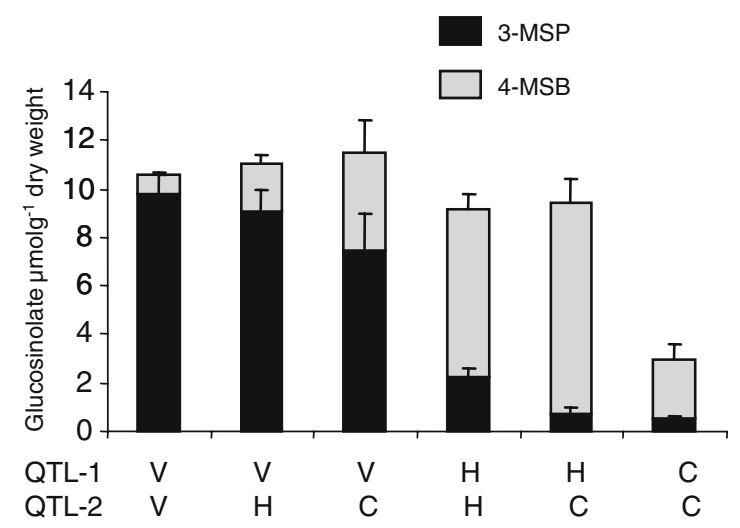

Fig. 4 Variation in the amount of 3-MSP and 4-MSB glucosinolate in broccoli lines of different genotypes at QTL-1 and QTL-2 when grown near Nottingham. The first three columns represent the glucosinolate content of the three genotypes at QTL- 1 and QTL-2 of the 70 plants from the 48-13 selfed population, in which there is segregation at QTL-2, but not QTL-1. The forth and fifth columns are the glucoisnolate content from the two genotypes from the $48-13 \times \mathrm{Br} 9$ cross, in which all plants are heterozygous at QTL-1, but vary at QTL-2. The sixth column represents Marathon, which has commercial alleles at both QTLs. Date are means $\pm \mathrm{SD}$. V - villosa; C - cultivar; H heterozygote 

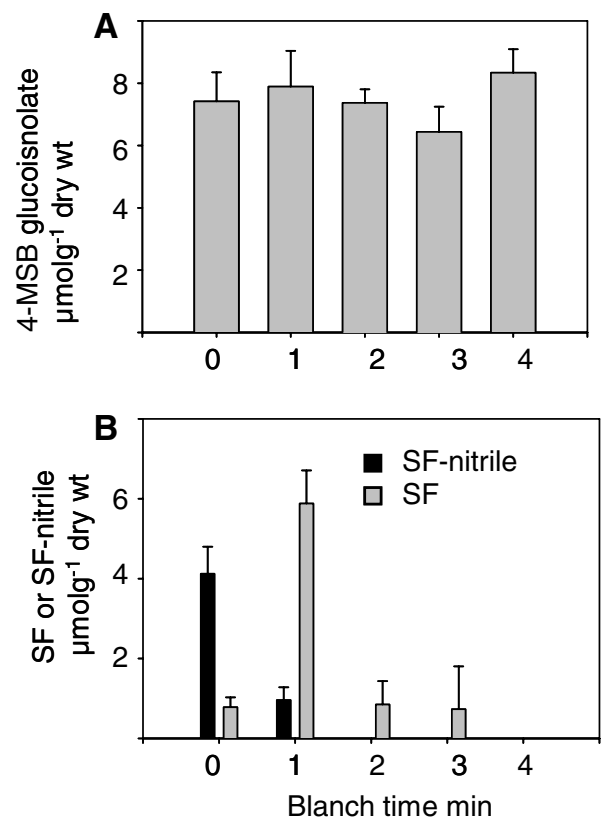

Fig. 5 The effect of blanching on (A) the glucosinolate content of florets without hydrolysis disruption post blanching, and (B) sulforaphane and sulforaphane nitrile production following hydrolysis. Data are means \pm SD. All florets are from the cultivar Marathon

The effect of processing on glucosinolate content

In addition to the effects of cooking, we evaluated whether methods for standard commercial processing for frozen broccoli would affect the difference in glucosinolate levels between high glucosinolate hybrids and standard cultivars. Thus, heads were harvested from field plots of the [48-13-4 × Br9] hybrid, Marathon and Heritage, cut into florets and then processed by blanching and freezing. Frozen florets were sealed within plastic bags and stored for 8 weeks at $-20 \times \mathrm{C}$.

Table 1 MSB glucosinolate content, sulforaphane content of soups after $90 \mathrm{~s}$ cooking and the percentage conversion of MSB glucosinolate into SF

\begin{tabular}{llcl}
\hline & $\begin{array}{l}\text { MSB } \mu \mathrm{molg}^{-1} \\
\text { dry wt }\end{array}$ & $\begin{array}{l}\text { SF } \\
\text { MolL }^{-1}\end{array}$ & $\begin{array}{l}\% \\
\text { conversion }\end{array}$ \\
\hline Marathon & $11.5 \pm 0.39 \mathrm{a}$ & $559 \pm 106.9 \mathrm{c}$ & 73 \\
Iron & $10.5 \pm 0.51 \mathrm{a}$ & $485 \pm 97.5 \mathrm{c}$ & 69 \\
$48 / 13 \times$ Br9 & $28.1 \pm 0.67 \mathrm{~b}$ & $1667 \pm 132.2 \mathrm{~d}$ & 89 \\
\hline
\end{tabular}

Values are means \pm SD. Values followed by the same letter are not significant different at $p>0.05$
The glucosinolate content of the [48-13-4 $\times \mathrm{Br} 9]$ hybrids was about three times the level of that found in Heritage, Marathon or the commercial samples (Table 2), indicating that the processing did little to alter the differences in glucosinolate content. When hydrolyzed, none of the genotypes produced any glucosinolate degradation products, unless additional myrosinase was added. Thus we conclude that while the blanching and freezing process had no effect on glucosinolate content, it denatured myrosinase.

\section{Discussion}

We are interested in developing broccoli that can deliver high levels of sulforaphane to test the hypothesis that SF, as opposed to other bioactive compounds found in broccoli, is the major anticarcinogenic agent. Previously, we reported the initial two phases of a breeding programme that introgressed segments of the genome of $B$. villosa into a commercial broccoli genetic background (Faulkner et al. 1998; Mithen et al. 2003) In the current study we extend the programme to develop broccoli hybrids suitable for human intervention studies and comparative analyses of phytochemical content and bioactivity with conventional cultivars. While the use of wild plants in plant breeding programmes is a useful source of novel alleles, especially for traits such as disease resistance, it is a problematic strategy particularly for high value vegetable crops in which appearance is a major trait to ensure commercial success. Thus, for breeding high glucosinolate broccoli, it is important to define the minimum number of introgressed segements required to increase glucosinolate content sufficiently to gain added health benefits. Previously, it had been shown that the presence of a single $B$. villosa allele at QTL-1 resulted in a two to three fold increase in glucosinolates, and affected the ratio of 3-MSP to 4-MSP (Mithen et al. 2003). When B. villosa alleles were homozygous at QTL-1, over $50 \%$ of the methylsulfinylalkyl glucosinolates were 3-MSP. The 3-MSP/4-MSB ratio can thus be used effectively as a marker for $B$. villosa alleles at QTL-1, and is easier to use than the absolute amount of glucosinolates which is 
Table 2 Glucosinolate content $\mu \mathrm{molg}^{-1}$ dry weight of frozen florets of the cultivars Heritage and Marathon and the high glucosinolate hybrid [48-13-4 $\times$ Br9] grown at Boston, UK, and three commercial sources of frozen broccoli purchased from local retailers, of unknown varieties

\begin{tabular}{|c|c|c|c|c|c|c|}
\hline & 3-MSP & 4-MSB & OHIND & IND & 1-MIND & 4-MIND \\
\hline Retail 1 & $0.8 \pm 0.36 a$ & $5.4 \pm 0.13 a$ & $0.2 \pm 0.01 \mathrm{a}$ & $3.2 \pm 0.15 \mathrm{a}$ & $0.8 \pm 0.02 \mathrm{ab}$ & $1.6 \pm 0.06 \mathrm{a}$ \\
\hline Retail 2 & $0.6 \pm 0.01 \mathrm{a}$ & $4.4 \pm 0.12 \mathrm{a}$ & $0.2 \pm 0.01 \mathrm{a}$ & $2.3 \pm 0.10 \mathrm{a}$ & $0.2 \pm 0.02 b$ & $0.6 \pm 0.02 b$ \\
\hline Retail 3 & $0.4 \pm 0.01 \mathrm{a}$ & $3.0 \pm 2.61 \mathrm{a}$ & $0.2 \pm 0.13 a$ & $2.8 \pm 2.45 a$ & $0.4 \pm 0.35 \mathrm{ab}$ & $0.9 \pm 0.76 \mathrm{ab}$ \\
\hline Heritage & $0.4 \pm 0.03 a$ & $5.0 \pm 0.33 a$ & $0.2 \pm 0.02 \mathrm{a}$ & $5.9 \pm 0.19 b$ & $0.7 \pm 0.05 a$ & $2.4 \pm 0.14 a$ \\
\hline Marathon & $0.7 \pm 0.04 a$ & $5.4 \pm 0.13 a$ & $0.2 \pm 0.01 \mathrm{a}$ & $3.8 \pm 0.19 \mathrm{ab}$ & $0.5 \pm 0.03 \mathrm{ab}$ & $1.6 \pm 0.17 \mathrm{a}$ \\
\hline$[48-13-4 \times$ Br9] & $3.6 \pm 0.09 b$ & $10.6 \pm 0.27 b$ & $0.2 \pm 0.01 \mathrm{a}$ & $3.1 \pm 0.18 \mathrm{a}$ & $0.6 \pm 0.01 \mathrm{ab}$ & $2.1 \pm 0.12 \mathrm{a}$ \\
\hline
\end{tabular}

Values are $\mu \mathrm{molg}^{-1}$ dry weight means $\pm \mathrm{SD}$; Figures followed by the same letter are not significantly different $p>0.05$. 3-MSP, 3-methylsulphinylpropyl; 4-MSB, 4-methylsulphinylbutyl; OHIND, Hydroxy-indolymethyl; IND, 3-indolylmethyl; 1-MIND, 1-methoxyindolylmethyl; 4-MIND, 4-methoxyindolylmethyl

affected by environmental factors. In the present study, we analyzed two populations that segregated for B. villosa alleles at QTL-2, and showed that while $B$. villosa alleles again altered the ratio of 3-MSP and 4-MSB, there was no overall affect on the total level of these two glucosinolates. Some caution must be exercised, as previous studies had indicated that under certain conditions, $B$. villosa alleles at this locus could increase 3-MSP without a concomitant fall in 4-MSB. As two segregating populations varied in their genotype at QTL-1, it was possible to see how $B$. villosa alleles at QTL-1 and QTL-2 interacted with each other to result in the expression of 3MSP and 4-MSB (Fig. 4).

While the selection criterion in the breeding programme was glucosinolate content, these metabolites are themselves not bioactive, and the aim is to develop broccoli that can deliver enhanced levels of SF and IB. Thus, it is important to demonstrate that high glucosinolate broccoli can produce an equivalent level of SF and IB. Previously, it was shown that when raw tissue of high glucosinolate breeding lines was macerated, resulting in glucosinolate hydrolysis, the majority of the glucosinolates were converted to isothiocyanates. In contrast, when raw tissue of the cultivar Marathon was hydrolysed, a large proportion of glucosinolates were converted to nitriles (Mithen et al. 2003). This difference in degradation products explained the greater than expected difference in the ability of these genotypes to induce QR on the basis of glucosinolate content. However, broccoli is not commonly eaten raw. Thus, prior to comparing glucosinolate degradation in Marathon and high glucosinolate broccoli, we investigated the affect of cooking on glucosinolate degradation from Marathon.

Cooking florets for six minutes by steaming or in a microwave oven had no affect on glucosinolate content if the tissue was not macerated before cooking. When macerated after cooking, isothiocyanates initially increased up to about two minutes of cooking, and then decreased rapidly upon further cooking, until no isothiocyanates were detected after cooking for more than four minutes. The amount of nitriles decreased upon cooking, and none were detected after 2-3 min. These results are consistent with previous studies (Matusheski et al. 2004) that have interpreted the degradation of glucosinolates as being dependent upon two proteins, firstly the enzyme myrosinase, and secondly a protein similar to the epithiospecifier protein that has been isolated from B. napus and A.thaliana. B. napus leaves contains predominantly 3-butenyl and 4-pentenyl glucosinolates. The ESP results in the unstable glucosinolate degradation products derived from myrosinase activity undergoing a rearrange to form epithionitriles, as opposed to isothiocyanates. In broccoli, it is thought that an ESP-like protein results in the intermediate product rearranging to form a nitrile, as opposed to an epithionitrile, as the broccoli glucosinolates lack the alkenyl side chain characteristic of glucosinolates in B. napus. ESP is rapidly denatured upon heating (Matusheski et al. 2004). Thus, mild cooking destroys ESP activity resulting in an increase in isothiocyanates (Fig. 5B). Further cooking results in myrosinase being denatured and thus a decrease in isothiocyanates (Fig. 5B).

Thus to compare isothiocyanate products, we cooked Marathon and high glucosinolate broccoli 
for $90 \mathrm{~s}$ in a microwave oven to prevent nitrile formation, and then homogenized the tissue to generate isothiocyanates. High glucosinolate broccoli produced about three times the level of SF than standard broccoli, confirming that increasing glucosinolates in broccoli can result in enhanced isothiocyanate production. Cooking for longer would denature myrosinase in both Marathon and high glucosinolate broccoli, and generation of isothiocyanate in vivo would depend upon thioglucosidase activity of the colonic microflora (Conaway et al. 2000; Getahun and Chung 1999).

As a further test of the commercial viability of high glucosinolate broccoli, we allowed a crop to be harvested and processed by freezing with standard commercial procedures, and analyzed the broccoli after it had been in a cold store for eight weeks. We found that, as in previous field experiments on other sites, the level of glucosinolate in high glucosinolate broccoli was about three fold higher than in Marathon, although the absolute level was lower than in previous studies. When we homogenized the frozen broccoli, no isothiocyanates were found unless we added myrosinase. Thus we concluded that while the blanching and freezing processes was effective in conserving the glucosinolates, it denatured the endogenous myrosinase.

To conclude, we have demonstrated that a segment of the genome of $B$. villosa can be introgressed into a standard broccoli genetic background. Hybrids derived from these lines are likely to deliver higher levels of SF when consumed. In addition, we have identified the genetic basis of IB production, so that broccoli lines could be developed which delivered high levels of IB, as opposed to SF. Furthermore, these new hybrids can be processed by freezing in a similar manner to standard cultivars. While the absolute levels of glucosinolates and their derivatives are influenced by both genetic and environmental factors, our data suggests that the high glucosinolate broccoli produce about three fold greater levels of glucosinolates than standard broccoli when grown at different sites and in different years. The production of enriched foods, such as described here, in addition to those enriched with other metabolites such as polyphenols, carotenoids or selenium containingcompounds (Finley 2005) produced either through agronomic practices or breeding may have an important role to play in efforts to reduce the burden of cancer on society. However, considerably more work needs to be done to establish whether they can provide health benefits, either to the general population or to high risk group.

Acknowledgements We thank the staff at the University of Nottingham for help with field work. We also thank Sarah Pettitt, Food and Consumer Division, Christian Salvesen, for processing the frozen broccoli, Martyn Watling and his staff for assistance with the broccoli cultivation at ADAS Terrington, and Martin Brittain and his staff for assistance with broccoli cultivation and harvesting near Boston, UK. Funding was provided by the University of Nottingham, Seminis Inc and the Biotechnology and Biological Sciences Research Council.

\section{References}

Abercrombie JM, Farnham MW, Rushing JW (2005) Genetic combining ability of glucoraphanin level and other horticultural traits of broccoli. Euphytica 143:145-151

Bennett R, Mellon FA, Rosa E, Perkins L, Kroon PA (2004) Profiling glucosinolates, flavonoids, alkaloids and other secondary metabolites in tissues of Azima tetracantha L. (Salvadoraceae). J Agri Food Chem (in press)

Bonnesen C, Eggleston IM, Hayes JD (2001) Dietary indoles and isothiocyanates that are generated from cruciferous vegetables can both stimulate apoptosis and confer protection against DNA damage in human colon cell lines. Cancer Res 61:6120-6130

Chen YR, Wang W, Kong AN, Tan TH (1998) Molecular mechanisms of c-Jun N-terminal kinase-mediated apoptosis induced by anticarcinogenic isothiocyanates. J Biol Chem 273:1769-1775

Chiao JW, Chung FL, Kancherla R, Ahmed T, Mittelman A, Conaway CC (2002) Sulforaphane and its metabolite mediate growth arrest and apoptosis in human prostate cancer cells. Int J Oncol 20:631-636

Conaway CC, Getahun SM, Liebes LL, Pusateri DJ, Topham DK, Botero-Omary M, Chung FL (2000) Disposition of glucosinolates and sulforaphane in humans after ingestion of steamed and fresh broccoli. Nutr Cancer 38:168-178

de Quiros HC, Magrath R, McCallum D, Kroymann J, Scnabelrauch D, Mitchell-Olds T, Mithen R (2000) alpha-keto acid elongation and glucosinolate biosynthesis in Arabidopsis thaliana. Theor Appl Genet 101:429-437

Dinkova-Kostova AT, Holtzclaw WD, Cole RN, Itoh K, Wakabayashi N, Katoh Y, Yamamoto M, Talalay P 
(2002) Direct evidence that sulfhydryl groups of keap1 are the sensors regulating induction of phase 2 enzymes that protect against carcinogens and oxidants. Proc Natl Acad Sci USA 99:11908-11913

Farnham MW, Stephenson KK, Fahey JW (2005) Glucoraphanin level in broccoli seed is largely determined by genotype. Hortscience 40:50-53

Farnham MW, Wilson PE, Stephenson KK, Fahey JW (2004) Genetic and environmental effects on glucosinolate content and chemoprotective potency of broccoli. Plant Breed 123:60-65

Faulkner K, Mithen R, Williamson G (1998) Selective increase of the potential anticarcinogen 4- methylsulphinylbutyl glucosinolate in broccoli. Carcinogenesis 19:605-609

Fimognari C, Nusse M, Berti F, Iori R, Cantelli-Forti G, Hrelia P (2002a) Cyclin D3 and p53 mediate sulforaphane-induced cell cycle delay and apoptosis in nontransformed human T lymphocytes. Cell Mol Life Sci 59:2004-2012

Fimognari C, Nusse M, Cesari R, Iori R, Cantelli-Forti G, Hrelia P (2002b) Growth inhibition, cell-cycle arrest and apoptosis in human T-cell leukemia by the isothiocyanate sulforaphane. Carcinogenesis 23:581-586

Finley JW (2005) Proposed criteria for assessing the efficacy of cancer reduction by plant foods enriched in carotenoids, glucosinolates, polyphenols and selenocompounds. Ann Bot (Lond) 95:1075-1096

Foo HL, Gronning LM, Goodenough L, Bones AM, Danielsen BE, Whiting DA, Rossiter JT (2000) Purification and characterisation of epithiospecifier protein from Brassica napus: enzymic intramolecular sulphur addition within alkenyl thiohydroximates derived from alkenyl glucosinolate hydrolysis. FEBS Lett 468:243-246

Gamet-Payrastre L, Li P, Lumeau S, Cassar G, Dupont MA, Chevolleau S, Gasc N, Tulliez J, Terce F (2000) Sulforaphane, a naturally occurring isothiocyanate, induces cell cycle arrest and apoptosis in HT29 human colon cancer cells. Cancer Res 60:1426-1433

Getahun SM, Chung FL (1999) Conversion of glucosinolates to isothiocyanates in humans after ingestion of cooked watercress. Cancer Epidemiol Biomarkers Prev 8:447-451 http://www.ukcrop.net/perl/ace/pic/ BrassicaDB? name $=$ N15_BBSRC-SSR\&class=Map)

Hu R, Kim BR, Chen C, Hebbar V, Kong AN (2003) The roles of JNK and apoptotic signaling pathways in PEITC-mediated responses in human HT-29 colon adenocarcinoma cells. Carcinogenesis 24:1361-1367

Jackson SJ, Singletary KW (2003) Sulforaphane: a naturally occurring mammary carcinoma mitotic inhibitor which disrupts tubulin polymerization. Carcinogenesis

Jeffery EH, Brown AF, Kurilich AC, Keck AS, Matusheski N, Klein BP, Juvik JA (2003) Variation in content of bioactive components in broccoli. J Food Compost Anal 16:323-330

Joseph MA, Moysich KB, Freudenheim JL, Shields PG, Bowman ED, Zhang Y, Marshall JR, Ambrosone CB (2004) Cruciferous vegetables, genetic polymorphisms in glutathione s-transferases $\mathrm{m} 1$ and $\mathrm{t} 1$, and prostate cancer risk. Nutr Cancer 50:206-213
Kim BR, Hu R, Keum YS, Hebbar V, Shen G, Nair SS, Kong AN (2003) Effects of glutathione on antioxidant response element-mediated gene expression and apoptosis elicited by sulforaphane. Cancer Res 63:7520-7525

Kore AM, Jeffery EH, Wallig MA (1993) Effects of 1isothiocyanato-3-(methylsulfinyl)-propane on xenobiotic metabolizing enzymes in rats. Food Chem Toxicol 31:723-9

Lambrix V, Reichelt M, Mitchell-Olds T, Kliebenstein DJ, Gershenzon J (2001) The Arabidopsis epithiospecifier protein promotes the hydrolysis of glucosinolates to nitriles and influences Trichoplusia ni herbivory. Plant Cell 13:2793-2807

Lin HJ, Probst-Hensch NM, Louie AD, Kau IH, Witte JS, Ingles SA, Frankl HD, Lee ER, Haile RW (1998) Glutathione transferase null genotype, broccoli, and lower prevalence of colorectal adenomas. Cancer Epidemiol Biomarkers Prev 7:647-652

Lowe AJ, Moule C, Trick M, Edwards KJ (2004) Efficient large-scale development of microsatellites for marker and mapping applications in Brassica crop species. Theor Appl Genet 108:1103-1112

Magrath R, Bano F, Morgner M, Parkin I, Sharpe A, Lister C, Dean C, Turner J, Lydiate D, Mithen R (1994) Genetics of aliphatic glucosinolates.1. sidechain elongation in Brassica napus and Arabidopsis thaliana. Heredity 72:290-299

Matusheski NV, Juvik JA, Jeffery EH (2004) Heating decreases epithiospecifier protein activity and increases sulforaphane formation in broccoli. Phytochemistry 65:1273-1281

Mithen R, Faulkner K, Magrath R, Rose P, Williamson G, Marquez J (2003) Development of isothiocyanateenriched broccoli, and its enhanced ability to induce phase 2 detoxification enzymes in mammalian cells. Theor Appl Genet 106:727-734

Munday R, Munday CM (2004) Induction of phase II detoxification enzymes in rats by plant-derived isothiocyanates: comparison of allyl isothiocyanate with sulforaphane and related compounds. J Agric Food Chem 52:1867-1871

Nachshon-Kedmi M, Fares FA, Yannai S (2004) Therapeutic activity of 3,3'-diindolylmethane on prostate cancer in an in vivo model. Prostate 61:153-160

Spitz MR, Duphorne CM, Detry MA, Pillow PC, Amos CI, Lei L, de Andrade M, Gu XJ, Hong WK, Wu XF (2000) Dietary intake of isothiocyanates: evidence of a joint effect with glutathione S-transferase polymorphisms in lung cancer risk. Cancer Epidemiol Biomarkers Prev 9:1017-1020

Wang L, Liu D, Ahmed T, Chung FL, Conaway C, Chiao JW (2004) Targeting cell cycle machinery as a molecular mechanism of sulforaphane in prostate cancer prevention. Int J Oncol 24:187-192

Wang W, Wang S, Howie AF, Beckett GJ, Mithen R, Bao Y (2005) Sulforaphane, erucin, and iberin up-regulate thioredoxin reductase 1 expression in human MCF-7 cells. J Agric Food Chem 53:1417-1421 